\title{
Artificial Neural Network (ANN) Based Empirical Interpolation of Precipitation
}

\author{
Rajesh Joshi \\ G. B. Pant National Institute of Himalayan Environment and Sustainable Development \\ Kosi-Katarmal, Almora-263643, Uttarakhand, India \\ E-mail: dr.rajeshjoshi@gmail.com
}

(Received June 17, 2016; Accepted August 18, 2016)

\begin{abstract}
Various climate impact studies need to generate estimates of climate variables at a given location based on values from other locations. It is well established fact that there are strong sensible physical linkages between global climate and local scale weather phenomenon. Therefore, empirical interpolation or downscaling has emerged as a prospective tool to relate atmospheric circulation patterns to surface variables for forecasting regional climate from GCM and RCM output dataset. In this paper, application of Artificial Neural Networks (ANNs) based soft computing model for empirical interpolation of precipitation in Himalayan region is attempted. This method uses ANNs to generate precipitation estimates for 11 districts of Uttarakhand state (India) given information from a lattice of surrounding locations. In the present paper, we have used Feed Forward Back Propagation (FFBP) algorithm to develop a Multilayer Perceptron ANN model for empirical downscaling of precipitation in Himalayan region. The model is developed using climate data of Climate Research Unit (CRU) and observed data for past 110 years (1901-2010). The robustness and suitability of the developed ANN model is verified by testing its applicability for 11 districts of Uttarakhand state. $80 \%$ of the data are used for training of the model and remain $20 \%$ are used for testing of the model. The performance evaluation of the model is tested by RMSE value. The study show that the model works quite well for climatic records of most of the district after bias correction.
\end{abstract}

Keywords - Empirical downscaling, artificial neural networks (ANNs), feed forward back propagation (FBBP) algorithm, precipitation, climate change, Himalaya.

\section{Introduction}

In recent years, considerable efforts have been devoted to investigate the effects of large scale climate change on rainfall variability in different parts of the world. Statistical and multiple nonlinear regression methods have been used for predicting rainfall on regional scale. To assess the impact of climate change, scientists depend heavily on global circulation models (GCMs); spatial resolution of these models remains quite coarse and varies from $2.5^{0} \times 2.5^{0}$ up to $8^{0} \times 10^{0}$ which is too coarse to assess the impacts of climate change on various ecosystems components at local and regional scale (Giorgi and Mearns, 1991; Clark, 1985). With such a coarse resolution, the regional and local details of the climate, influenced by spatial heterogeneities in the regional physiography particularly in the Himalaya, are lost. Therefore, there is need to convert the GCM outputs into a reliable data set with higher spatial resolution, with daily rainfall and temperature time series at scale of a watershed or region to which impacts of climate are to be investigated. Since, many impacts models require information at scales of $25 \mathrm{~km}$ or even less; therefore, to generate regional information on climate, interpolation of GCMs output to finer resolution is required. Even though GCMs can be run at high resolutions, still results from such models need to be downscaled for individual sites or locations for impact studies which enables construction of climate change scenarios for regional level at daily/ monthly time-scales. 
International Journal of Mathematical, Engineering and Management Sciences

Vol. 1, No. 3, 93-106, 2016

https://dx.doi.org/10.33889/IJMEMS.2016.1.3-011

\subsection{Existing Downscaling and Interpolation Methods}

Variety of techniques, such as inverse distance weighted averages, splines, kriging, and radial basis functions, have been used for spatial interpolation (Hewitson and Crane, 1996). All these techniques use information present in known sample locations to interpolate values for other locations; yet, there are no criteria for prioritizing these techniques. The existing literature describes efforts made by various researchers (Giorgi and Mearns, 1991; Hewitson and Crane, 1996; Joubert and Hewitson, 1997; Wilby and Wigley, 1997; Wilby et al., 1998) to downscale climate data generated by GCM simulations. Broadly, the downscaling techniques are divided into two major categories; process-based (dynamic) and empirical (statistical) approaches (Hewitson and Crane, 1996; Wilby and Wigley, 1997). Dynamic downscaling is the process of extracting local-scale information by developing regional climate models (RCMs) with the coarse GCM data as boundary conditions. This approach uses a fine-resolution climate model having a global or smaller domain to produce fine-scale information (Dickinson et al., 1989; Russo and Zack, 1997). Required boundary condition includes three-dimensional atmospheric fields at threehour or six-hour intervals. Though the dynamical downscaling produces a complete range of physically consistent meteorological outputs which are useful for research on physical mechanisms of the local scale climate change, but since these methods are computationally demanding, expensive and require large data sets, hence, may not be very practical (Giorgi and Mearns, 1991; Hewitson and Crane, 1996).

Empirical interpolation or downscaling, on the other hand, starts with the hypothesis that regional climate is result of interplay of overall atmospheric and oceanic circulation as well as regional topography, land-sea distribution and land use (Von Storch et al., 2000). This approach uses empirical techniques to produce fine-scale climate information wherein relationships between regional-scale climate features and large-scale features are developed by analyzing observations (Wilby and Wigley, 2000). Key assumptions in this approach are that the future climate patterns can be derived from linear combinations of weather from previously observed patterns and changes predicted using coarse-resolution models are correct at fine spatial scales. Basically, it is a two step process: (i) development of relationship between local climate variables (e.g. temperature and precipitation) and large scale predictors (e.g. pressure fields) and (ii) application of such relationships to the output of GCM experiments to simulate climate characteristic at regional and local scale when suitable observed data are available to derive the relationship. To eliminate first order biases from these models delta change approach, where changes in quantities from a coarse simulation are added or multiplied to fine-scale historical climate data, is adopted (Imbert and Benestad, 2005). Statistical downscaling is computationally inexpensive, but produces results for only a few meteorological quantities such as precipitation and near-surface temperatures (Zorita and Storch, 1999).

Empirical methods of downscaling generally use transfer functions to relate local conditions to large-scale climate features and are valid only within the range of the sample data (Katz and Parlange, 1976). Accuracy of these transfer functions is, therefore, not very perfect. The relation between synoptic-scale features and local climatological fields often nonlinear and changes with atmospheric circulation. These difficulties, along with inherent spatial dependencies, create need for complex mathematical specifications and estimation techniques (Bogardi et al., 1993; Matyasovsky et al., 1994). ANNs can approximate nonlinear relations and their derivatives without knowing the true nonlinear function; therefore are used to make accurate predictions for highly nonlinear systems (Werbos, 1974; Rumelhart et al., 1986; Fischer and Gopal, 1994; Gopal and Scuderi, 1995). Consistent with these capabilities, ANNs are being used to analyze and 
International Journal of Mathematical, Engineering and Management Sciences

Vol. 1, No. 3, 93-106, 2016

https://dx.doi.org/10.33889/IJMEMS.2016.1.3-011

produce climate information (Gardner and Dorling, 1998), investigate the effect of atmospheric circulation on local precipitation (Hewitson and Crane, 1996; Cavazos, 1997; Crane and Hewitson, 1998) develop transfer functions for predicting snowfall from grid scale information generated by GCMs (McGinnis, 1994), and estimate convective rainfall and recognize cloud merger from satellite data (Zhang and Scofield, 1994).

Downscaling or interpolation techniques have been used in the past for deriving finer-scale weather information from numerical weather prediction models. Some more common approaches found in the literature are regression techniques or piecewise interpolations using a linear or nonlinear formulation. The simplest approach is to build multiple regression models relating free atmosphere grid point values to surface variables (Hewitson and Crane, 1996). An alternative to linear regression is to use piecewise linear or nonlinear interpolation such as "kriging" method. The potential of this approach has been demonstrated by (Biau et al., 1999) to relate local precipitation to large-scale pressure distributions. Another non-linear approach is based on artificial neural networks (ANNs), which are generally more powerful than other techniques, although the interpretation of the dynamical character of the relationships is less easy. Applications of ANN have successfully been implemented by (Hewitson and Crane, 1996; Cavazos, 1997; Wilby et al., 1998; Crane and Hewitson, 1998; McGinnis, 1994; and Weichert and Bürger, 1998).

In Himalaya, topographic features play an important role to govern climate at regional level; therefore, information of climatic variable is required at micro level to study and assess impact of climate change on different sectors. So far, because of the complex topography and scarcity of observed data, very few studies have been carried out on dynamical/empirical downscaling of climate variables over the Himalayan region. With the hypothesis that ANN technique may address many of these difficulties and therefore may be useful to downscale GCM output (Hornik et al., 1989), this study is attempted with an objective to evaluate potential of ANNs to downscale the precipitation in Himalaya. In this study ANNs, a soft computing technique, is used for empirical downscaling and spatial interpolation of precipitation to generate precipitation estimates for 11 districts of Uttarakhand state in North-Western Himalaya. The hypothesis is addressed by quantifying relationship between the CRU data and observed rainfall data in different districts of Uttarakhand State of India. In the present paper, Feed Forward Back Propagation (FBBP) approach is used to develop a Multilayer Perceptron ANN model for empirical downscaling of precipitation.

Evaluation of this paper is described in six sections. Section 2 describes brief about study area and its climate. Section 3 describes the methodology that demonstrates the ability of ANNs to interpolate/downscaling of precipitation with special focus on dataset used and training and testing of ANN model. Section 4 encompasses results and discussion part of the paper. Based on the potential indicated by the results in section 4, section 5 describes several methodological issues that confront analysts who seek to use ANNs to downscale output from GCMs along with future research areas.

\section{Study Area}

\subsection{Physiographic Features}

Uttarakhand state, situated on the southern slope of Himalayas, has geographical extent of $28^{0} 43^{\prime} 45^{\prime \prime}$ to $31^{0} 28^{\prime} 10^{\prime \prime} \mathrm{N}$ latitude and $77^{0} 34^{\prime} 5^{\prime}$ "to $81^{0} 2^{\prime} 25^{\prime \prime} \mathrm{E}$ longitude. The state has 13 districts and total geographical area of approximately $53,483 \mathrm{~km}^{2}$ which is $1.63 \%$ of the total area of the 
International Journal of Mathematical, Engineering and Management Sciences

Vol. 1, No. 3, 93-106, 2016

https://dx.doi.org/10.33889/IJMEMS.2016.1.3-011

country. The state borders with Nepal and Tibet on the east, central Himalayas on the north, and Haryana and Himachal Pradesh on northwest (Fig. 1). Geographically the state has four Mountain zones, namely; foot hills, lesser Himalaya, Greater Himalaya and Trans-Himalaya. These mountain ranges are the store house of perpetual snow and glaciers and have gifted Northern India a perennial river the mighty Ganges and its tributaries namely: Bhagirathi, Alaknanda, Yamuna, Sharda, Gori and Dhauli. Geography of Uttarakhand is so much varied that it has been geographically divided into two parts, the western half is known as Garhwal and the eastern region as Kumaun (India State of Forest Report, 2011).

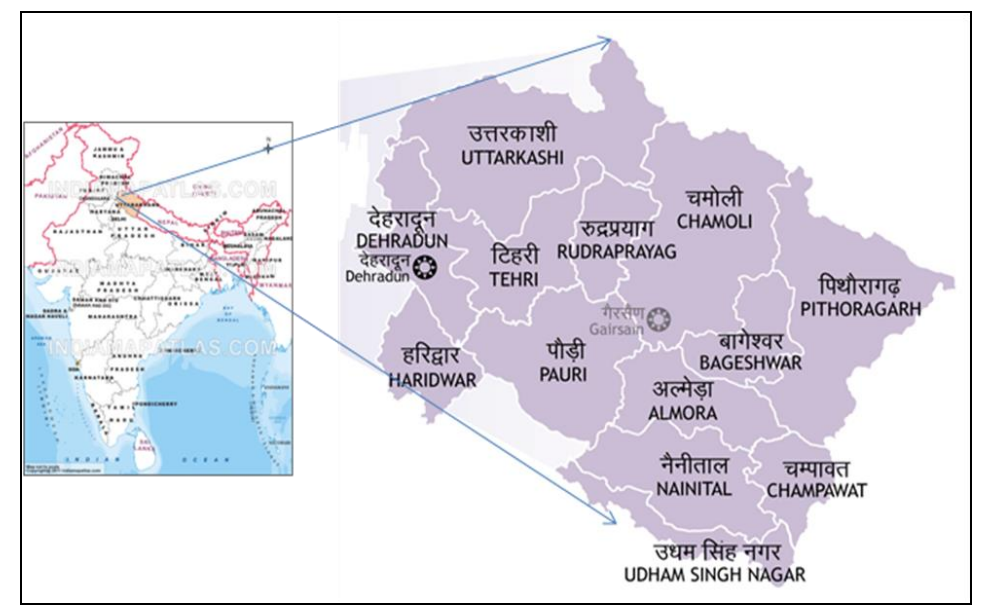

Fig.1. Location of study area

\subsection{Climate}

Climate of Uttarakhand state is distinguished in its two diverse divisions; the major hilly terrain and the smaller plains. The state has temperate climate except in the plain areas where climate is tropical. The northern part of the state, enveloped by the mighty Himalaya, reflect complete traits of Himalayan climate and exert great influence on monsoon and rainfall patterns. In the southern foothills, the average summer temperatures vary between $30^{\circ} \mathrm{C}$ to $40^{\circ} \mathrm{C}$. In middle Himalaya, the summer temperature is usually around $20^{\circ} \mathrm{C}$ to $30^{\circ} \mathrm{C}$; however winters temperature sometime drops below the freezing point. The high altitude areas of Himalaya (at more than $4000 \mathrm{~m}$ ), being covered by snow and ice, have cold and dry weather throughout the year. These areas become inaccessible during October to April due to heavy snowfall. The eastern edges of the Himalayan ranges are subject to heavy rainfall while the western division is relatively dry. However, in Gangetic plains, summers are extremely hot and humid with temperature crossing the $40^{\circ} \mathrm{C}$ mark and winters are relatively quite cold with temperatures dipping below $5^{\circ} \mathrm{C}$ at times. The climate and vegetation of different regions of this state vary with the altitude of its location; the climate also varies within the mountains in accordance with the altitude.

\section{Methodology}

\subsection{Data Used}

For the present study we have used monthly precipitation data of past 110 years (1901-2010) available from Climate Research Unit (CRU TS2.1) for 1901-2002 and observed precipitation data for 2003-2010. The CRU TS2.1 data, from the Tyndall Centre for Climate Change Research, School of Environmental Sciences, University of East Anglia, UK, consists of interpolated 
International Journal of Mathematical, Engineering and Management Sciences

Vol. 1, No. 3, 93-106, 2016

https://dx.doi.org/10.33889/IJMEMS.2016.1.3-011

$\left(0.5^{0} \times 0.5^{0}\right.$ lat-long grid) global monthly rainfall, temperature, relative humidity, and cloud cover. The CRU precipitation data for all 11 districts of Uttarakhand state (except for Bageshwar and Rudraprayag for which data were not available) are used. Further, observed rainfall data (for 2003-2010) for all the districts under study is obtained from Indian Meteorological Department (IMD), Pune, India. For few districts primary rainfall data generated by the Institute for 5 years (i.e. 2004-2009) under the Participation of youth in Real-time/ field Observation to Benefit the Education in Uttarakhand state (U-PROBE) project supported by the Department of Science and Technology (DST), Government of India is also used. This project was coordinated by the Institute in collaboration with different schools, universities, research organizations and state Government. Brief description of dataset used in the present study is given in Table1.

\begin{tabular}{|c|c|c|c|c|}
\hline Source & Time Slice & Name of station/ District & Purpose & $\begin{array}{l}\text { Spatial scale/ } \\
\text { resolution }\end{array}$ \\
\hline $\begin{array}{l}\text { Climate Research } \\
\text { Unit (CRU), UK }\end{array}$ & $1901-2002$ & $\begin{array}{llr}\text { All } 11 & \text { districts of Uttarakhand } \\
\text { (except } & \text { Bageshwar } & \text { and } \\
\text { Rudraprayag) } & & \\
\end{array}$ & $\begin{array}{l}\text { Development \& training } \\
\text { of ANN model }\end{array}$ & $\left(0.5^{0} \times 0.5^{0}\right.$ grid $)$ \\
\hline IMD, Pune (India) & $2004-2010$ & $\begin{array}{l}\text { All } 11 \text { districts of Uttarakhand } \\
\text { (except Bageshwar and } \\
\text { Rudraprayag) }\end{array}$ & $\begin{array}{l}\text { Testing of developed } \\
\text { ANN model }\end{array}$ & Observed station data \\
\hline $\begin{array}{l}\text { U-PROBE (DST, } \\
\text { India) }\end{array}$ & $2004-2009$ & Almora and Pithoragarh & $\begin{array}{l}\text { Gap filling \& testing of } \\
\text { developed model }\end{array}$ & Observed station data \\
\hline
\end{tabular}

Table 1. Dataset used in the present study

\subsection{Pre-Processing of Dataset}

The CRU meteorological data for all 11 districts of Uttarakhand state is extraycted from the data generated for the entire world by Mitchell and Jones (2005) using a simple approximation and linear averaging from the girded data of CRU dataset. The IMD data set are acquired from different stations in study district and averaged for entire district. Bias correction is done using observed U-PROBE data and regression model described in section 3.5. Data gaps in IMD dataset, if any, are filled using observed U-PROBE data for that particular district. Further, gaps in the U-PROBE dataset are filled using linear interpolation methods for which mathematical models were developed to estimate the missing values. As required for development of model, complete data set is divided into two parts: (i) $80 \%$ data are used for training of the developed ANN model, and (ii) remaining $20 \%$ data are used for testing/validation of the model. Dataset for training and testing are created by random separation process from entire data set. The CRU data are used for training of the developed ANN model whereas observed data from IMD and UPROBE are used for validation of the developed model.

\subsection{Training of ANN Model}

To investigate potential of ANNs for empirical downscaling of precipitation, ANN model is trained on $80 \%$ dataset to predict precipitation for 11 different districts of the study area. The ANNs used in the present study are Multilayer Perceptron (MLP) networks (Fig. 2). 
International Journal of Mathematical, Engineering and Management Sciences

Vol. 1, No. 3, 93-106, 2016

https://dx.doi.org/10.33889/IJMEMS.2016.1.3-011

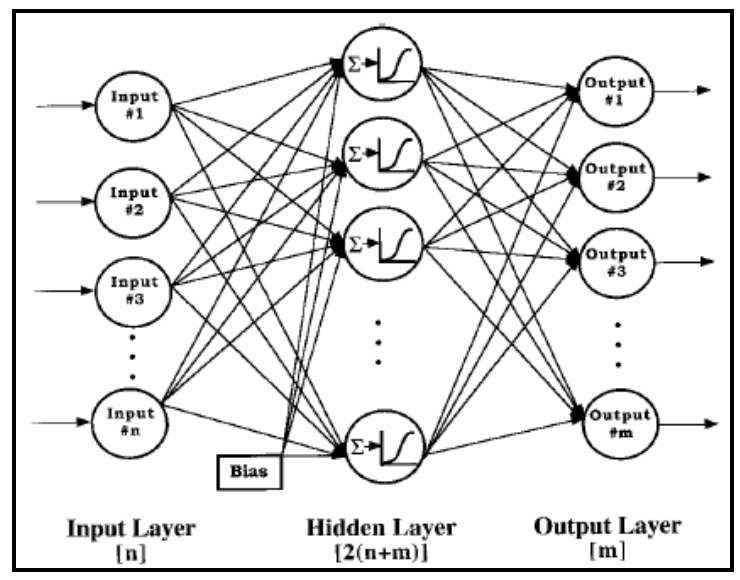

Fig. 2. Architeture for ANN model

MLP, a feed forward network, implements mappings from the input pattern space to the output space. In MLP, information is transmitted through the connections between its neurons which cover its initial and past states. A MLP can be trained with the standard back propagation algorithm and mathematically can be expressed as

$a_{j}^{1}(t)=F\left(\sum_{i=1}^{R} w_{j, i}^{1} p_{i}(t)+b_{j}^{1}\right), \quad 1 \leq j \leq S_{1}$

$a_{k}^{2}(t)=G\left(\sum_{j=1}^{S_{1}} w_{k, j}^{2} a_{j}^{1}(t)+b_{k}^{2}\right), \quad 1 \leq k \leq S_{2}$

Where, $t$ denotes a discrete time, $R$ is the number of input signals, $S_{1}$ and $S_{2}$ are the numbers of hidden and output neurons respectively, $w_{j, i}^{1}$ and $w_{k, j}^{2}$ are the weight matrices of hidden and output layers, $b_{j}^{1}$ and $b_{k}^{2}$ are the bias vectors of hidden and output layers, $p i(t)$ is the input matrix, $a_{1}$ and $a_{2}$ are the output vectors of the hidden and output layers, and $F$ and $G$ are the activation functions of the hidden and output layers, respectively. Tan-sigmoid transfer function is used for development and training of Networks. The Feed-forward Back Propagation Network (FBPN) is used to interpolate/downscale precipitation which is expressed mathematically as

$X_{k}=X_{k}-\alpha_{k} g_{k}$

where, $X_{k}$ is the vector of current weight and biases, $\alpha_{k}$ is current gradient, and $g_{k}$ is the learning rate. We train back propagation neural network to learn the relation between input and output vectors. During the training phase, connection weights are adjusted to minimize root mean square error (RMSE) between desired outputs estimated from the ANN model. Weights of the neural network are adjusted as follows:

$$
w_{i, j}(\text { new })=w_{i, j}(\text { old })+\beta \delta_{i} O_{j}+\alpha\left\lfloor\Delta w_{i, j}(\text { old })\right]
$$


International Journal of Mathematical, Engineering and Management Sciences

Vol. 1, No. 3, 93-106, 2016

https://dx.doi.org/10.33889/IJMEMS.2016.1.3-011

Where $w_{i, j}=$ weight associated with the $j^{\text {th }}$ node in the $i^{\text {th }}$ layer, $\beta=$ momentum factor, $\alpha=$ learning rate, $O_{j}=$ output from $j^{\text {th }}$ node, $\delta_{i}=$ error signal $=\left(t_{i}-O_{j}\right) O_{j}\left(1-O_{j}\right), t_{i}=$ observed value for the $i^{\text {th }}$ output node.
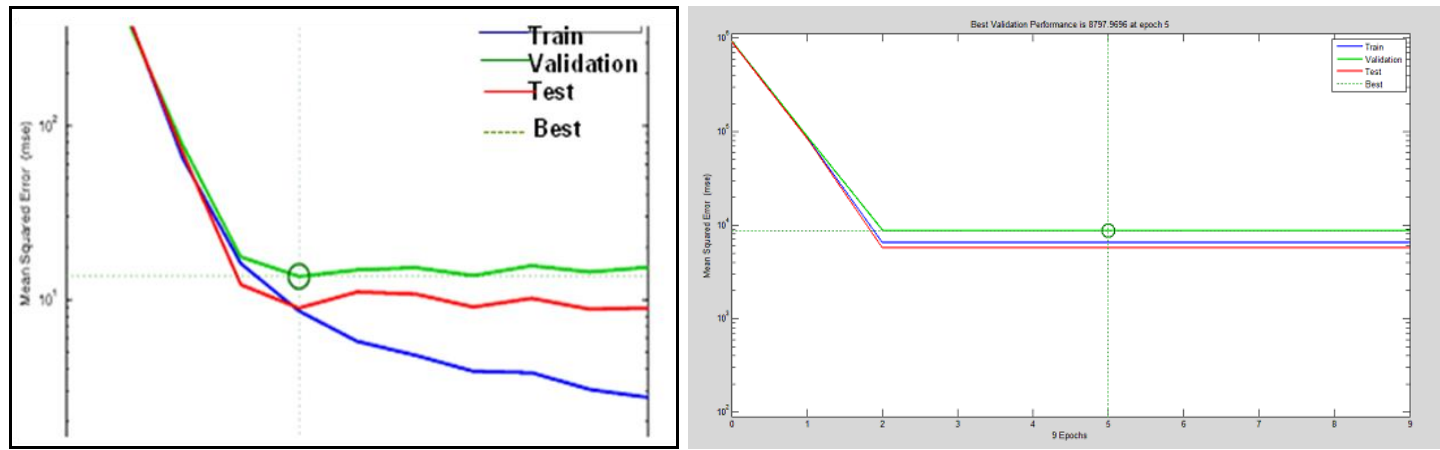

Fig. 3. Training of the ANN model
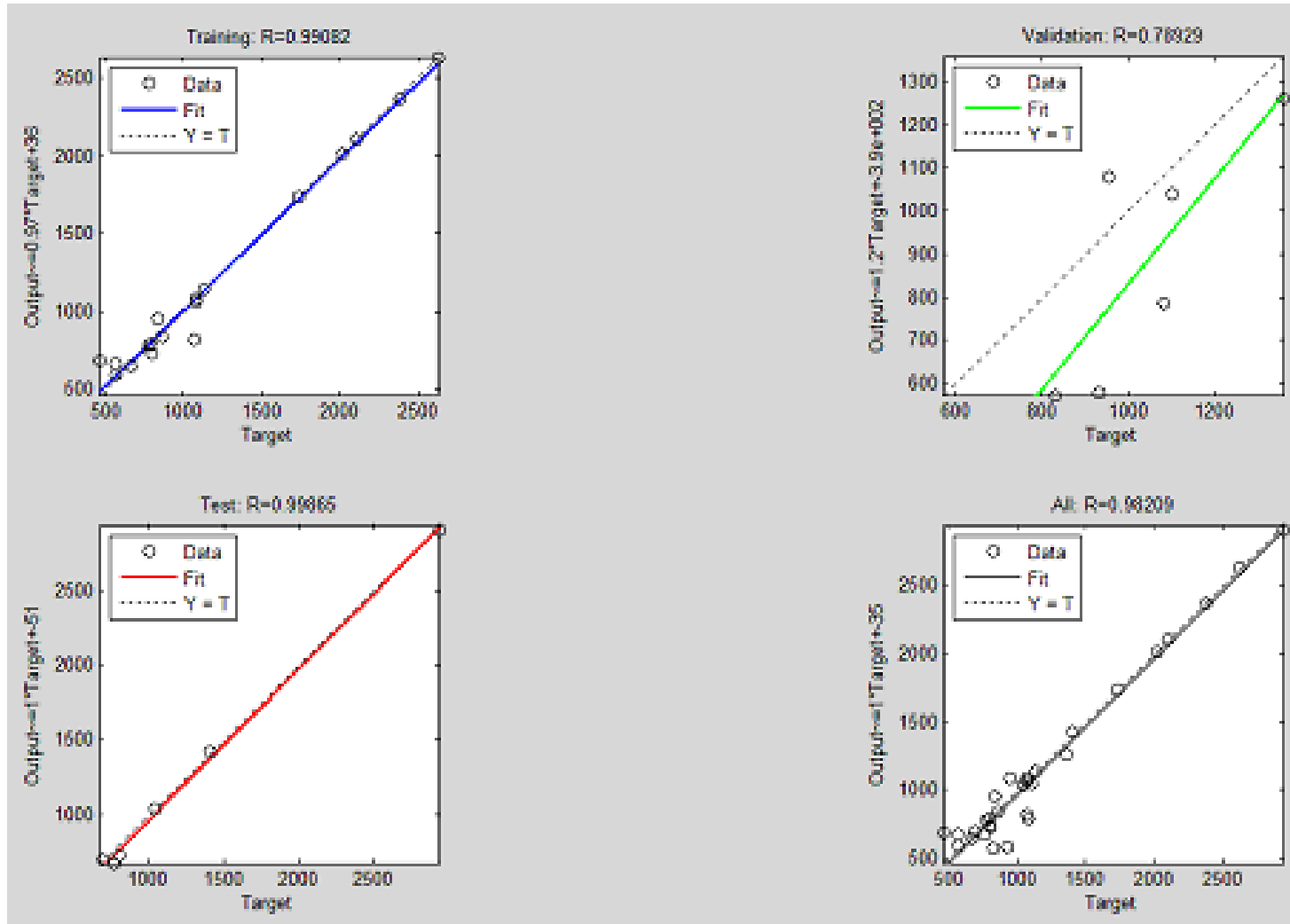

Fig. 4. Performance of ANN model during training of the model

Initially, four different ANN models are developed by varying weights, changing transfer function and using different set of neurons. The RMSE reaches its minimum at 200 iterations at 16 ecpoch (Fig. 3). Beyond this point increasing the number of iterations does not change the 
International Journal of Mathematical, Engineering and Management Sciences

Vol. 1, No. 3, 93-106, 2016

https://dx.doi.org/10.33889/IJMEMS.2016.1.3-011

RMSE significantly. Based on the results obtained during training phase best performing model is adopted for training of the network. Performance of training of ANN model is depicted in Fig. 4, which shows that the ANN has been trained quite nicely. The suitability of training of ANNs is illustrated by correlation values obtained during different stages, namely training $(r=0.99)$, validation $(r=0.79)$, testing $(r=0.99)$, and overall $(r=0.98)$.

\subsection{Testing and performance evaluation of developed ANN model}

Testing of the developed ANNs is carried out on remaining $20 \%$ of dataset and performance evaluation of developed ANNs is tested on target output. The target output and ANN model output are plotted in Fig. 5(a-i) for comparison purpose and results of performance evaluation of the developed model are presented in Table 2. Initially, for a few districts, we found comparatively small and non-significant correlation values and consequently the higher RMSE value this may be attributed to infrequent occurrence of high precipitation month and gaps in the training data set.

\begin{tabular}{|c|c|c|c|c|c|}
\hline \multirow{2}{*}{ Model } & \multirow{2}{*}{ Hidden Nodes } & \multicolumn{2}{|c|}{ Value of correlation coefficient $(\boldsymbol{r})$} & \multicolumn{2}{|c|}{ MSE } \\
\cline { 3 - 6 } & & Training & Validation & Training & Validation \\
\hline ANN-M1 & 2 & 0.78 & 0.09 & 23097.62 & 23485.64 \\
\hline ANN-M2 & 3 & 0.83 & 0.53 & 8999.05 & 13996.86 \\
\hline ANN-M3 & 4 & 0.80 & 0.21 & 10533.53 & 16745.13 \\
\hline ANN-M4 & 5 & 0.88 & 0.36 & 1723.56 & 18249.41 \\
\hline ANN-M5 & 6 & 0.97 & 0.04 & 11345.34 & 18342.43 \\
\hline
\end{tabular}

Table 2. Performance statistics for various ANN models

In such a situation, to reduce error and improve model efficiency, we performed bias corrections to reproduce improved annual precipitation time series for only those districts/stations for which the correlation values are relatively poor and non-significant and RMSE values are comparatively higher (Fig. 6). In the present study following equation is used for bias correction (Snell, 2000).

$$
R_{i, j}=\alpha+\beta \hat{R}_{i, j}+\gamma_{i, j}
$$

Where, $R_{i, j}$ is historical value of precipitation at station $i$ in the year $j, \alpha$ and $\beta$ are regression coefficients, $\hat{R}_{i, j}$ value of precipitation generated by ANN, and $\gamma_{i, j}$ is random error. The developed model is then applied on improved time series for spatial interpolation/downscaling. After performing bias correction, value of the correlation coefficient $(r)$ improved significantly from 0.76 to 0.92 for Champawat, 0.70 to 0.90 for Dehradun, 0.61 to 0.89 for Pauri Garhwal, and 0.55 to 0.84 for U. S. Nagar. The bias correction, applied to the original times series, consequently also improved root mean square error values for the abovementioned districts significantly. The $\mathrm{R}^{2}$ values are then calculated for improved values of correlation coefficient. Improved performance of ANN model is depicted in Table 3 wherein values of $r$ and RMSE, obtained after bias correction, are presented. 
International Journal of Mathematical, Engineering and Management Sciences

Vol. 1, No. 3, 93-106, 2016

https://dx.doi.org/10.33889/IJMEMS.2016.1.3-011

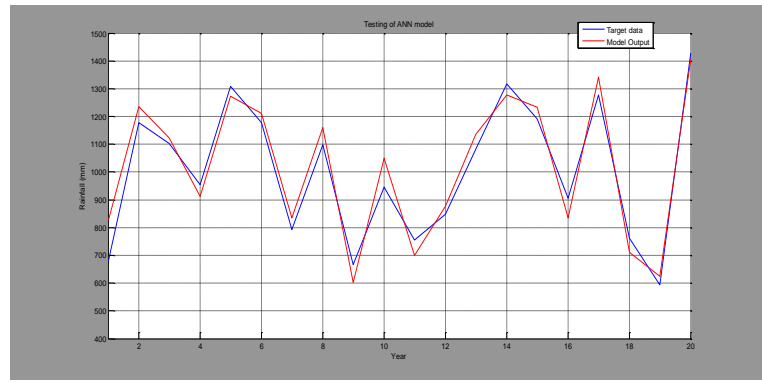

(a) Almora $(r=0.98)$

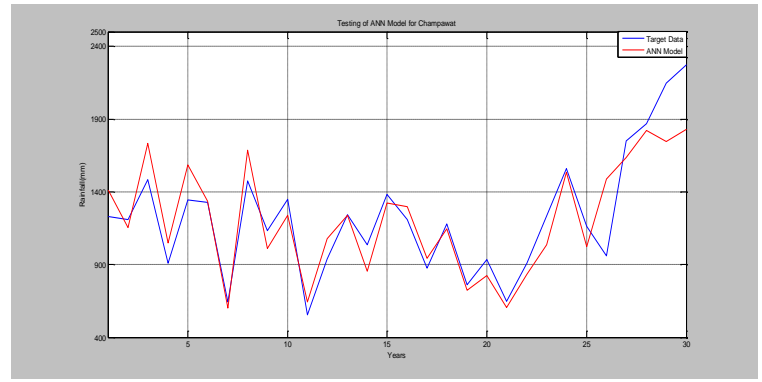

(c) Champawat $(r=0.7)$

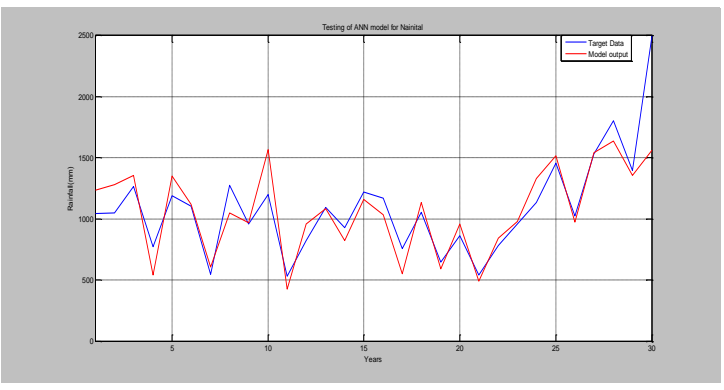

(e) Haridwar $(r=0.9)$

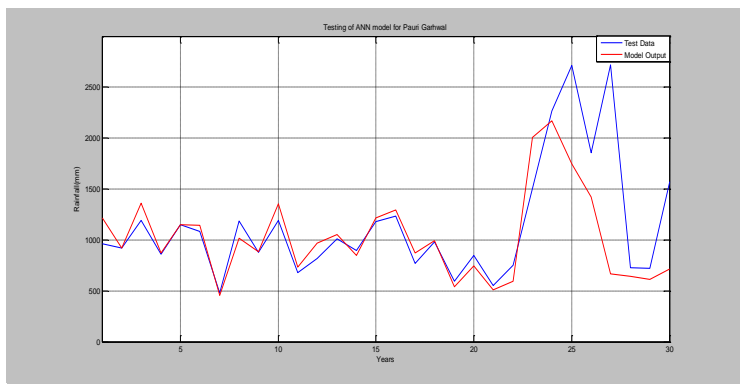

(g) Pauri Garhwal $(r=0.61)$

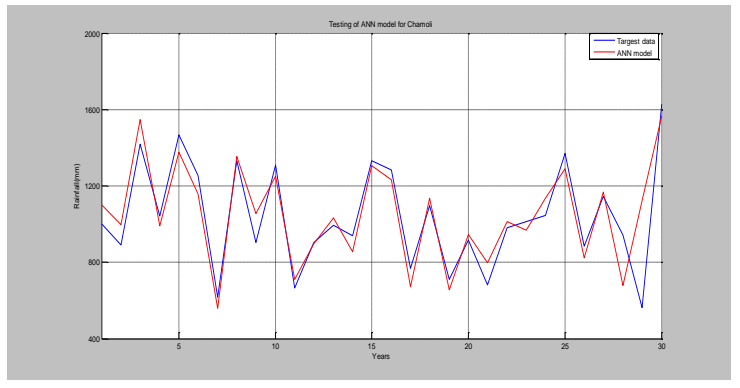

(b) Chamoli $(r=0.97)$

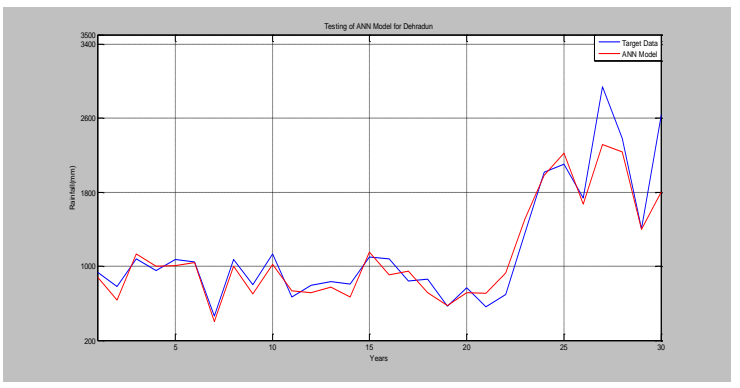

(d) Dehradun $(r=0.9)$

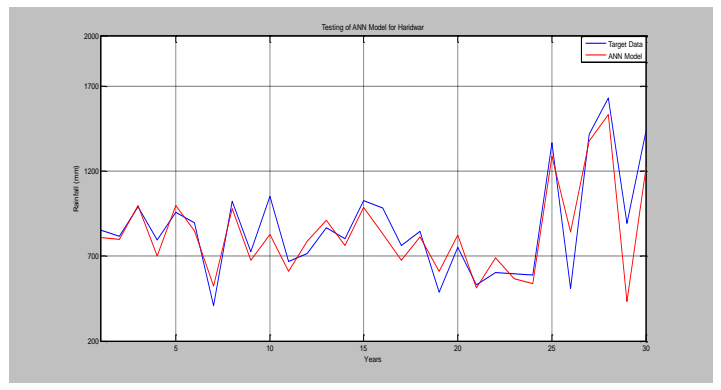

(f) Nainital ( $r=0.87)$

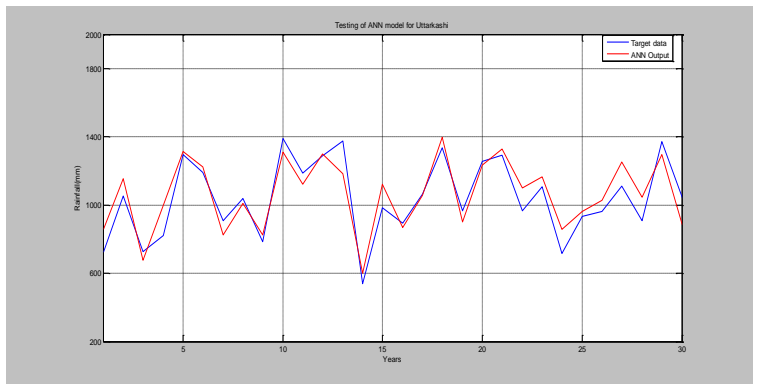

(h) Pithoragarh $(r=0.86)$ 
International Journal of Mathematical, Engineering and Management Sciences

Vol. 1, No. 3, 93-106, 2016

https://dx.doi.org/10.33889/IJMEMS.2016.1.3-011

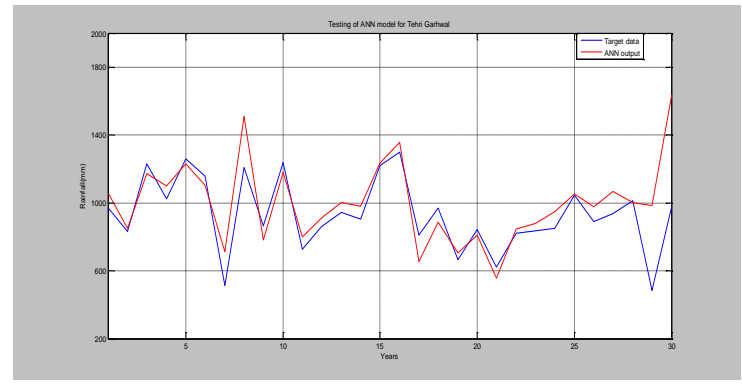

(i) Tehri Garhwal $(r=0.6)$

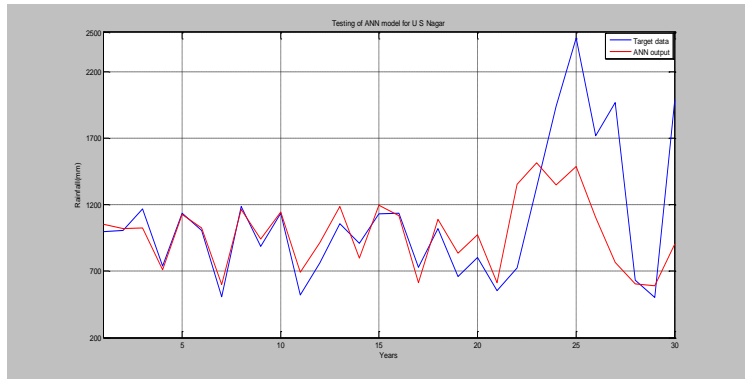

(j) Uttarkashi $(r=0.82)$

Fig. 5 (a-j). Testing of developed ANN Model for various districts of Uttarakhand State

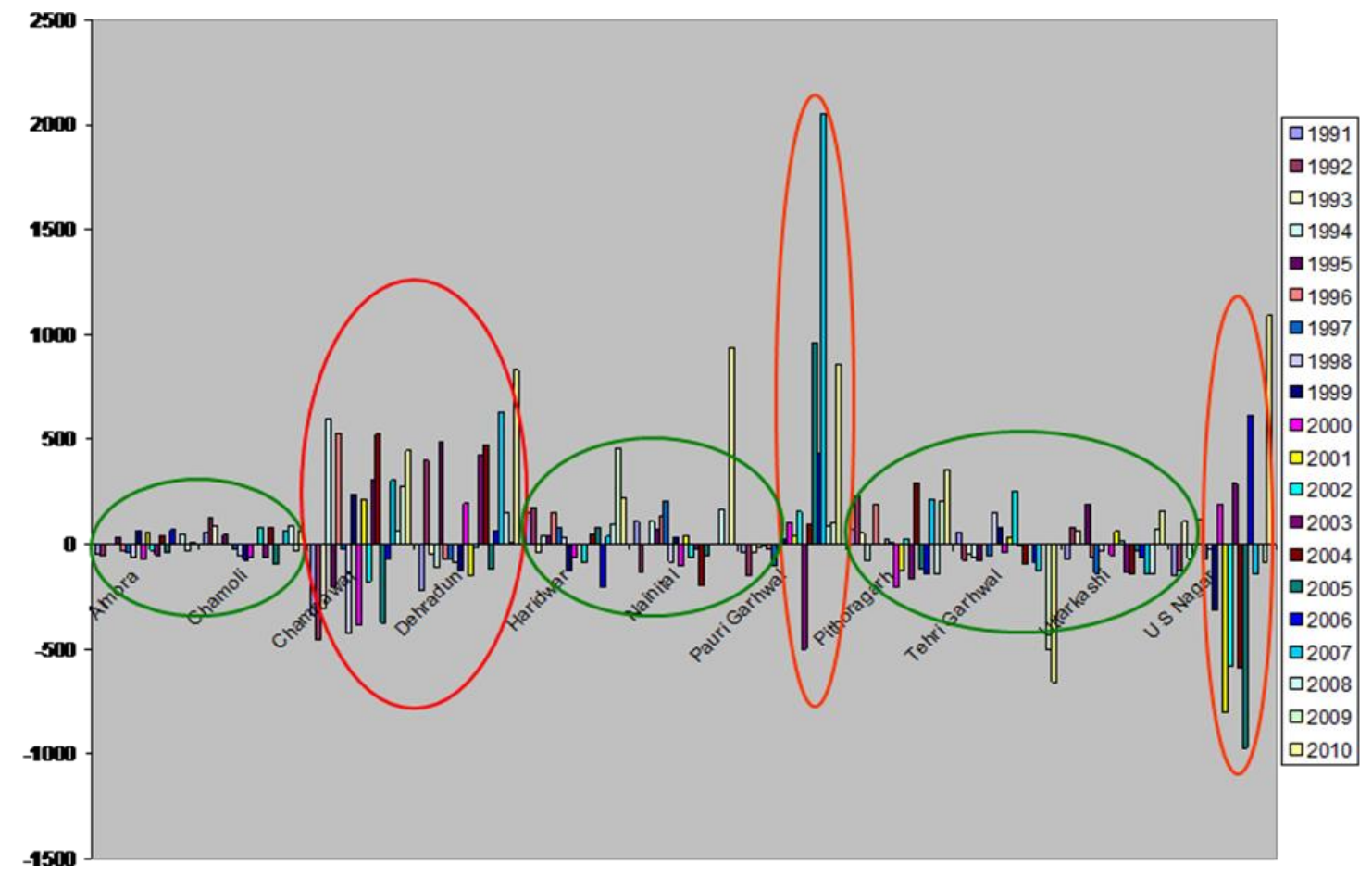

Fig. 6. Error estimate curve for the developed ANN model 
International Journal of Mathematical, Engineering and Management Sciences

Vol. 1, No. 3, 93-106, 2016

https://dx.doi.org/10.33889/IJMEMS.2016.1.3-011

\begin{tabular}{|c|l|c|c|c|c|c|}
\hline S. No. & District/Station & $\begin{array}{c}\text { Correlation } \\
\text { coefficient (r) }\end{array}$ & $\begin{array}{c}\text { Value of r (after } \\
\text { bias correction) }\end{array}$ & $\mathbf{R}^{\mathbf{2}}$ & RMSE & RMSE (after bias correction) \\
\hline 1 & Almora & 0.98 & 0.98 & 0.96 & 74.5 & 74.5 \\
\hline 2 & Chamoli & 0.97 & 0.97 & 0.94 & 66.2 & 66.2 \\
\hline 3 & Champawat & 0.76 & $\mathbf{0 . 9 2}$ & 0.84 & 97.7 & $\mathbf{8 4 . 7}$ \\
\hline 4 & Dehradun & 0.70 & $\mathbf{0 . 9 0}$ & 0.81 & 97.6 & $\mathbf{8 3 . 8}$ \\
\hline 5 & Haridwar & 0.90 & 0.90 & 0.81 & 82.7 & 82.7 \\
\hline 6 & Nainital & 0.87 & 0.87 & 0.75 & 81.6 & 81.6 \\
\hline 7 & Pauri Garhwal & 0.61 & $\mathbf{0 . 8 9}$ & 0.79 & 99.6 & $\mathbf{8 4 . 2}$ \\
\hline 8 & Pithoragarh & 0.86 & 0.86 & 0.73 & 66.1 & 66.1 \\
\hline 9 & Tehri Garhwal & 0.96 & 0.96 & 0.92 & 56.4 & 56.4 \\
\hline 10 & Uttarkashi & 0.82 & 0.82 & 0.67 & 68.8 & $\mathbf{8 . 8 4}$ \\
\hline 11 & U S Nagar & 0.55 & 0.70 & 98.5 & $\mathbf{8 2 . 3}$ \\
\hline
\end{tabular}

Table 3. Improved performance evaluation of ANN model

\section{Results and Discussion}

To investigate suitability of ANNs for empirical interpolation of precipitation Multilayer Perceptron (MLP) ANN model is trained over CRU climate data for 11 districts of Uttarakhand state in India. The complete data set is divided into two parts; $80 \%$ data are used for training/ calibration and remaining $20 \%$ data are used for validation/testing of the model. Four ANN models with different training steps, transfer function, neurons and returns are developed and their performance was compared. Finally, a 3-layer MLP model with 2 neurons and minimum RMSE is selected and results of the best performing model are only presented in this study. Minimum RMSE is obtained at 200 iterations at 16 ecpoch and hence the best model is adopted for training of the network. Performance and suitability of ANN is illustrated by correlation coefficient $(r)$ values, between time series of individual district and estimated through ANNs, obtained during different stages of the model testing. The estimated values of $r$ for different districts show that the model performs nicely during validation phase also. However, for few districts higher peaks are not properly captured by the developed model. This may be due to data gaps in the observed rainfall data which were filled by interpolation and comparatively less observed data set for training of the model. Therefore, the linearly interpolated values may not be captured by the ANNs trained over the dataset generated from CRU grid dataset and creates noise while applying on the testing dataset. Also, if the training data is long and contains noise, the ANN begins to fit the noise present in the training data. In such cases, when an over trained ANN is presented with data that it has not yet seen (i.e. data with the same relationship as training data but new and different noise), then its performance becomes lower in comparison to the situation when it has only learned the actual relationship during training.

The results show that ANNs account for much of the temporal and spatial variation in precipitation across all districts. Performance of ANNs is found low for Uttarkashi district (i.e. station 10), where it accounts for $67 \%$ of the variation over time, and best for Almora district (i.e. station 1), where it accounts for $96 \%$ of the variation over time. The model performance was further improved after carrying out the bias correction as described in section 3.5. RMSE values are found consistent with the performance of developed ANNs as indicated by the values for $R^{2}$ (Table 2). The maximum RMSE values of ANNs is found for Puari Garhwal $(99.6 \mathrm{~mm}$ ) followed by US Nagar $(98.5 \mathrm{~mm})$, Champawat $(97.7 \mathrm{~mm})$ and Dehradun $(97.6 \mathrm{~mm})$. Similarly, relatively minimum RMSE values are obtained for Tehri Garhwal $(56.4 \mathrm{~mm})$, Pithoragarh $(66.1 \mathrm{~mm})$, and Chamoli $(66.2 \mathrm{~mm})$. The most accurate predictions are obtained for the districts with uniform variation (i.e. having comparatively less difference between maximum and minimum totals) and moderate amount of precipitation. This suggests that the developed ANN model have learned the 
International Journal of Mathematical, Engineering and Management Sciences

Vol. 1, No. 3, 93-106, 2016

https://dx.doi.org/10.33889/IJMEMS.2016.1.3-011

patterns that are common in the data, but not able to locate patterns associated with values of precipitation that deviate from the mean monthly precipitation significantly. This may be due to the gaps in training data set and infrequent occurrence of high precipitation months. The errors in estimated values may be also linked to inconsistencies between predictors and predictand data used as the "observed data", suggesting the need for improving observed records and reanalysis data sets in the Himalayas.

The results of this analysis reflects that the developed ANN model have captured pattern of training data set and hence can be useful to interpolate precipitation data from a grid structure to interior points with a fairly high degree of accuracy. The results plotted in Fig. 5(a-i), where values are interpolated using the MLP ANN model are presented, indicate that the interpolations generated by ANN differ in the degree of systematic prediction. There could be several possible reasons for the under/over fitting of the developed model, such as violation of non-linearity assumptions, synoptic classification that produced the predictors, lack of information required for atmospheric stability (e.g., atmospheric pressure, vertical vorticity of wind), or a relative measure of humidity as input variables. This implies that the interpolations can be improved by including atmospheric circulation patterns (CPs) in the model. Also, training of the ANNs can be improved by representing the temporal structure of the data in a more realistic manner wherein autoregressive structure can be integrated with spatial structure. An autoregressive structure increases the number of input nodes because values for precipitation at the output stations depend on current and previous values for precipitation. Therefore, the interpolation may be improved by more temporal representations and by addition of other atmospheric input variables. These modifications can be implemented with relatively little change in the overall ANN architecture.

\section{Conclusion}

During past few decades, interpolation of climate variables has become an established tool to relate atmospheric circulation to surface variables. It is well established fact that there are strong sensible physical linkages between global climate and local scale weather phenomenon. Therefore, interpolation or downscaling has emerged as a prospective tool to relate atmospheric circulation patterns to surface variables for forecasting the regional climate from global circulation data. A variety of empirical downscaling techniques (such as inverse distance weighted averages, splines, kriging, and radial basis functions) have been developed for spatial interpolation; these methods vary in complexity and use information present in known sample locations to interpolate values for other locations. Relation between synoptic-scale features and local climatological fields often is highly nonlinear and changes with atmospheric circulation. These difficulties along with spatial dependencies, that are inherent to many climatological fields, create need for complex mathematical specifications and estimation techniques. Also, it remains uncertain whether the empirical approaches can be applied to non-stationarity of climate change. ANNs having property to approximate nonlinear relations and their derivatives without knowing the true nonlinear function, may address many of these difficulties and therefore can be a useful tool to interpolate climate model outputs. The mathematical flexibility of ANNs offers opportunity to make use of this technique for empirical interpolation of climate variables. In the present paper, application of ANNs for empirical downscaling and spatial interpolation of precipitation in Himalaya is attempted. Here we have used FBBP algorithm to develop an MLP ANN model for empirical interpolation or downscaling of precipitation by generating precipitation estimates for 11 districts of Uttarakhand state in India. The developed model is applied on climate data of past 110 years (1901-2010) and robustness/suitability of the ANNmodel is verified. $80 \%$ of the data are used for training of the model and remain $20 \%$ are used for 
International Journal of Mathematical, Engineering and Management Sciences

Vol. 1, No. 3, 93-106, 2016

https://dx.doi.org/10.33889/IJMEMS.2016.1.3-011

testing of the model. The performance evaluation of the model is tested by RMSE value. The results show that the developed ANN model works quite well for most of the district after bias correction and values $r$ for different districts shows that the model performs nicely during testing phase. However, for few districts the higher peaks are not captured properly by the developed model which may be attributed to data gaps in the observed dataset and comparatively small time series of observed data set for training of developed ANNs. The present study also paves the way for further modifications in available techniques and provides opportunities for development of robust techniques for empirical interpolation or downscaling of climate variables in Himalayan region. With advancement in computational techniques, the possibility of greater use and refinement of these techniques with introduction of new methods has also increased. One possible future research area is integration of physical processes that govern the relationship between the atmosphere and surface variables in empirical interpolation or downscaling models. Identification of temporal and spatial scales at which these relationships remain stable, and development of better predictor selection criteria could be other possible areas of research in this direction.

\section{Acknowledgements}

Author is thankful to the director, GBPNIHESD for providing necessary facilities and support during course of this study. The climate dataset provided to the scientific community by the Tyndall Centre for Climate Change Research, UK is duly acknowledged.

\section{References}

Biau, G., E. Zorita, H. von Storch and H. Wackernagel (1999). Estimation of precipitation by kriging in EOF space. Journal of Climate, 12, 1070-1085.

Bogardi, I., I. Matyasovsky, A. Bardossy, and L. Duckstein (1993). Application of a space-time stochastic model for daily precipitation using atmospheric circulation patterns. Journal of Geophysical Research, 98 (D9), $16653-16667$.

Cavazos, T. (1997). Downscaling large-scale circulation to local rainfall in North-Eastern Mexico. International Journal of Climatology, 17, 1069-1082.

Clark, W., (1985). Scales of climate change. Climatic Change, 7, 5-27.

Crane, R. G., \& Hewitson, B. C. (1998). Doubled CO2 precipitation changes for the Susquehanna basin: down-scaling from the GENESIS general circulation model. International Journal of Climatology, $18(1), 65-76$.

Dickinson, R. E., Errico, R. M., Giorgi, F., \& Bates, G. T. (1989). A regional climate model for the western United States. Climatic Change, 15(3), 383-422.

Fischer, M. M., \& Gopal, S. (1994). Artificial neural networks: a new approach to modeling interregional telecommunication flows. Journal of Regional Science, 34(4), 503-527.

Forest Survey of India (2011). India State of Forest Report-2011

Gardner, M. W., \& Dorling, S. R. (1998). Artificial neural networks (the multilayer perceptron) - a review of applications in the atmospheric sciences. Atmospheric Environment, 32(14), 2627-2636.

Giorgi, F., \& Mearns, L. O. (1991). Approaches to the simulation of regional climate change: a review. Reviews of Geophysics, 29(2), 191-216.

Gopal, S., \& Scuderi, L. (1995). Application of artificial neural networks in climatology: A case study of sunspot prediction and solar climate trends. Geographical Analysis, 27(1), 42-59.

Hewitson, B. C., \& Crane, R. G. (1992). Large-scale atmospheric controls on local precipitation in tropical Mexico. Geophysical Research Letters, 19(18), 1835-1838. 
International Journal of Mathematical, Engineering and Management Sciences

Vol. 1, No. 3, 93-106, 2016

https://dx.doi.org/10.33889/IJMEMS.2016.1.3-011

Hewitson, B. C., \& Crane, R. G. (1996). Climate downscaling: techniques and application. Climate Research, 7(2), 85-95.

Hornik, K., Stinchcombe, M., \& White, H. (1989). Multilayer feedforward networks are universal approximators. Neural Networks, 2(5), 359-366

Imbert, A., \& Benestad, R. E. (2005). An improvement of analog model strategy for more reliable local climate change scenarios. Theoretical and Applied Climatology, 82(3-4), 245-255.

Katz, R. W., \& Parlange, M. B. (1996). Mixtures of stochastic processes: application to statistical downscaling. Climate Research, 7(2), 185-193.

Matyasovszky, I., Bogardi, I., Bardossy, A., \& Duckstein, L. (1994). Local temperature estimation under climate change. Theoretical and Applied Climatology, 50(1-2), 1-13.

McGinnis, D. L. (1994). Predicting snowfall from synoptic circulation: a comparison of linear regression and neural network methodologies. In Neural Nets: Applications in Geography (pp. 79-99). Springer Netherlands.

Mitchell, T. D., \& Jones, P. D. (2005). An improved method of constructing a database of monthly climate observations and associated high-resolution grids. International Journal of Climatology, 25(6), 693712.

Rumelhart, D. E., G. E. Hinton, and Williams, R. J. (1986). Learning representations by back-propagating errors. Nature, 323, 533-536.

Russo, J. M., \& Zack, J. W. (1997). Downscaling GCM output with a mesoscale model. Journal of Environmental Management, 49(1), 19-29.

Snell, S. E., Gopal, S., \& Kaufmann, R. K. (2000). Spatial interpolation of surface air temperatures using artificial neural networks: Evaluating their use for downscaling GCMs. Journal of Climate, 13(5), 886895.

Von Storch, H. (2000). On the use of "inflation" in downscaling. Journal of Climate (in press).

Von Storch, H. and Zwiers, F.W. (1999). Statistical Analysis in Climate Research. Cambridge University Press, ISBN 052145071 3, 528 pp.

Weichert, A., \& Bürger, G. (1998). Linear versus nonlinear techniques in downscaling. Climate Research, 10(2), 83-93.

Werbos, P. (1974). Beyond regression: new tools for prediction and analysis in the behavioral sciences. Ph.D. dissertation, Dept. of Applied Mathematics, Harvard University, 453 pp.

Wilby, R. L., \& Wigley, T. M. L. (1997). Downscaling general circulation model output: a review of methods and limitations. Progress in Physical Geography, 21(4), 530-548.

Wilby, R. L., T. Wigley, D. Conway, P. Jones, B. Hewitson, J. Main, and D. Wilks, (1998). Statistical downscaling of general circulation model output: A comparison of methods. Water Resources Research, 34 (11), 2995-3008.

Zhang, M., \& Scofield, R. A. (1994). Artificial neural network techniques for estimating heavy convective rainfall and recognizing cloud mergers from satellite data. Remote Sensing, 15(16), 3241-3261.

Zorita, E., \& Von Storch, H. (1999). The analog method as a simple statistical downscaling technique: comparison with more complicated methods. Journal of Climate, 12(8), 2474-2489. 